\title{
Avaliação físico-química e quantificação de metais potencialmente tóxicos em águas superficiais do rio Jauru
}

\author{
Geilson Rodrigues da Silva $^{1}$; Hygor Rodrigues de Oliveira ${ }^{2}$; Taniel Ferreira da Cruz ${ }^{3}$; Lucas \\ Pereira Gandra ${ }^{4}$ \\ geilsonrodrigues367@gmail.com
}

1. Universidade Federal de Mato Grosso do Sul - Campo Grande, MS, Brasil 2. Instituto Federal de Mato Grosso do Sul - Coxim, MS, Brasil 3. E. E. Leontino Alves de Oliveira - Rio Negro, MS, Brasil 4. Fundação Educacional de Coxim. E.E. Viriato Bandeira - Coxim, MS, Brasil

Histórico do Artigo:

Recebido em: 11 de junho de 2018

Aceito em: 16 de outubro de 2018 Publicado em: 28 de dezembro de 2018

Resumo: 0 Rio Jauru compõe a sub-bacia do Alto Taquari que junto com a sub-bacia do Baixo Taquari representam um dos principais afluentes da bacia do Rio Paraguai, responsável pelo ciclo das águas no bioma do pantanal. Ao longo do Rio Jauru existem jazidas de minerais e pequenos garimpos e na região também, localizam-se grandes lavouras de soja e milho que empregam agrotóxicos, podendo ocasionar contaminações ambientais. Desse contexto selecionou-se os principais parâmetros físico-químicos, utilizados na literatura sendo o: ( $\mathrm{pH}$, alcalinidade, oxigênio dissolvido, condutividade elétrica, turbidez, sólido totais dissolvidos, cor verdadeira e dureza total) e quantificação dos metais (Ni, $\mathrm{Cd}, \mathrm{Cu}, \mathrm{Mn}$ e Pb) nas águas superficiais do Rio Jauru. As amostras foram obtidas em três pontos de coleta no decorrer de três meses consecutivos. As determinações físicoquímicas foram realizadas a partir de adaptação de métodos disponíveis na literatura e a avaliação de metais ocorreu pela Espectrometria de Absorção Atômica em Chama. Apenas a cor verdadeira apresentou concentrações acima do permitido pela legislação do conselho nacional do meio ambiente, enquanto o cobre foi 0 único metal que apresentou concentração acima do permitido. Os resultados expostos no presente estudo, não apontaram para uma contaminação ambiental nos pontos e nos meses de análise.

Palavras-chave: Bacia Hidrográfica, Mineração, Poluentes, Espécies Metálicas, Qualidade Ambiental

\section{Physical-chemical evaluation and quantification of potentially toxic metals in surface waters of Jauru river}

\begin{abstract}
The Jauru River comprises the sub of the Hight Taquari which together with the sub of the lower Taquari represent one of the main tributaries of the Paraguay River basin, responsible for the water cycle in the Pantanal Biome. Along the Jauru River there are mineral deposits and small mining and in the region also, large soybean and maize crops that employ pesticides are located, and may cause environmental contamination. This context selected the main physico-chemical parameters used in the literature: (pH, alkalinity, dissolved oxygen, electrical conductivity, turbidity, Total solid dissolved, true Color and overall hardness) and quantification of metals $(\mathrm{Ni}, \mathrm{Cd}, \mathrm{Cu}, \mathrm{Mn}$ and $\mathrm{Pb})$ in the surface waters of the Jauru River. Samples were obtained at three collection points in the course of three consecutive months. The physico-chemical determinations were made from the adaptation of methods available in the literature and the evaluation of metals occurred by the flame atomic absorption spectroscopy. Only the true color showed concentrations above the permitted legislation of the national environmental council, while copper was the only metal that presented concentration above the permitted. The results exposed in this study did not point to environmental contamination in the points and months of Analysis.
\end{abstract}

Keywords: Hydrographic Basin, Mining, Pollutants, Metallic Species, Environmental Quality. 


\title{
Evaluación físico-química y cuantificación de metales potencialmente tóxicos en aguas superficiales del río Jauru
}

\begin{abstract}
Resumen: El río Jauru compone la subcuenca del Alto Taquari que junto con la subcuenca del Bajo Taquari representan uno de los principales afluentes de la cuenca del Río Paraguay, responsable del ciclo de las aguas en el bioma del pantanal. A lo largo del río Jauru existen yacimientos de minerales y pequeños garimpos y en la región también, se ubican grandes cultivos de soja y maíz que emplean agrotóxicos, pudiendo ocasionar contaminaciones ambientales. En este contexto se seleccionaron los principales parámetros físico-químicos, utilizados en la literatura siendo: ( $\mathrm{pH}$, alcalinidad, oxígeno disuelto, conductividad eléctrica, turbidez, sólidos totales disueltos, color verdadero y dureza total) y cuantificación de los metales ( $\mathrm{Ni}, \mathrm{Cd}, \mathrm{Cu}, \mathrm{Mn}$ y $\mathrm{Pb}$ ) en las aguas superficiales del Río Jauru. Las muestras se obtuvieron en tres puntos de recolección durante tres meses consecutivos. Las determinaciones fisicoquímicas se realizaron a partir de la adaptación de los métodos disponibles en la literatura y la evaluación de metales ocurrió por la Espectrometría de Absorción Atómica en Chama. Sólo el color verdadero presentó concentraciones por encima de lo permitido por la legislación del consejo nacional del medio ambiente, mientras que el cobre fue el único metal que presentó concentración por encima de lo permitido. Los resultados expuestos en el presente estudio, no apunta a una contaminación ambiental en los puntos y en los meses de análisis.

Palabras clave: Cuenca hidrográfica, Minería, Contaminantes, Especies metálicas, Calidad Ambiental.
\end{abstract}

\section{INTRODUÇÃ0}

0 Mato Grosso do Sul é um estado do Brasil banhado pela Bacia do Rio Paraguai sendo esse rio o principal responsável pelo ciclo das águas no bioma do pantanal. Esse corpo hídrico apresenta diversos afluentes dentre estes destaca-se o Rio Taquari, que banha a cidade de Coxim-MS. Por sua vez, este rio é dividido entre bacias denominadas predominantemente de Baixo e Alto taquari (BRASIL, 2006).

Dentre essas bacias o Rio Jauru tem grande relevância histórica para a cidade de Coxim-MS. Esse rio tem sua nascente na serra do taquari, constituindo o limite geográfico de diversas cidades da região Norte de Mato Grosso do Sul, além de banhar o povoado de mesmo nome do rio. A história do Rio Jauru é paralela com o desenvolvimento da cidade de Coxim, passando pelas monções que tinham como objetivo descobrir novas jazidas de minerais (FERREIRA-NETO, 2004).

Nesse sentido Ferreira-Neto (2004), indicaram que no rio Jauru encontram-se os seguintes recursos minerais:

\footnotetext{
"Encontra-se no cascalho e rochas, os seguintes minerais no Rio Jauru: Ouro, diamante, quartzo rolado transparente (pingo d'água), quartzo branco arrendondado (0vo de pomba), turmalina (pretinha), magnetito (ferragem), granada (chicória) e outras pedras coroadas (azulinhas), areia com magnetito, lâmina de oligisto, bornita, hematito vermelho e concreções de sílica com óxidos de ferro..." (FERREIRA-NETO, 2004, p.55.)
} 
Percebe-se que a localidade é propensa à atividade mineradora e ainda persistem pequenos garimpos para a exploração de minerais e mineralóides localizados às margens do rio.

Além disso, a atividade agrícola na região representa uma importante fonte de renda para o município, com o predomínio de grandes propriedades com extensas áreas cultivadas com soja e milho em regime de monocultura. E devido a essa atividade é comum o emprego de agrotóxicos, sendo que na pesquisa de Maraschim (2003) identificou níveis elevados de agrotóxicos nos rios Jauru, Paraguai, Itiquira, Coxim, Taquari, Negro, Apa, Aquidauana, Salobra e Miranda. Nesse cenário torna-se importante investigar a presença de metais potencialmente tóxicos dentre esses níquel, cádmio, cobre, manganês, cromo e chumbo, que são utilizados na formulação de agrotóxicos, e são um dos indicativos de contaminação ambiental (AMARAL, 2012).

Além da agricultura o entorno do Rio Jauru é ocupado com pastagens cultivadas, que sofrem constantemente erosão agravada pelo desmatamento nas encostas dos morros diminuindo a fertilidade dos solos (BRASIL, 1997). Esse rio banha a vila do Jauru que tem na pesca profissional, no turismo e na atividade agropecuária a base da sua economia e a população ribeirinha utiliza as águas superficiais para consumo próprio após tratamento convencional.

Nesse sentido, o Rio Jauru, enquadra-se na classificação da resolução 357 do Conselho Nacional do Meio Ambiente- Conama (BRASIL, 2005), sendo um corpo hídrico de água doce de classe 3. Essa classificação leva em consideração a utilização do rio para abastecimento de residências, irrigação de áreas plantadas, a pesca amadora e profissional e a dessedentação de animais, tais como praticados pela população do vilarejo. A resolução do Conama (BRASIL, 2005), estabelece valores máximos permitidos para diversos parâmetros, sendo que vários destes foram utilizados no presente estudo, no qual foram realizadas comparações entre os valores obtidos nas análises com os valores máximo permitido pelo Conama.

Diante do exposto o presente estudo teve como objetivo determinar os seguintes parâmetros físico-químicos: potencial hidrogeniônico $(\mathrm{pH})$, alcalinidade, oxigênio dissolvido, condutividade elétrica, turbidez, sólidos totais dissolvidos, cor verdadeira e dureza total que foram escolhidos pois fazem parte de um rol de análises físico-químicas indicadas para estipular a qualidade de corpos hídricos (BRASIL, 2013). Assim como, avaliar a concentração de metais $(\mathrm{Ni}, \mathrm{Cd}, \mathrm{Cu}, \mathrm{Mn}$ e Pb) nas águas superficiais do Rio Jauru, bacia do Rio Paraguai. Esses 
Avaliação físico-química e quantificação de metais potencialmente tóxicos em águas superficiais do rio Jauru

metais são empregados na investigação dos problemas de contaminação ambiental em recursos hídricos (MESQUISTA, 2014; UECHI et al, 2017).

\section{MATERIAL E MÉTODOS}

As amostras foram coletadas em triplicata nos períodos de 26/08/2017, 29/09/2017 e 21/10/2017, demarcados no GPS Garmim, sendo o ponto 1: S 18038' 52”. 2; W 54 21.1”, para 0

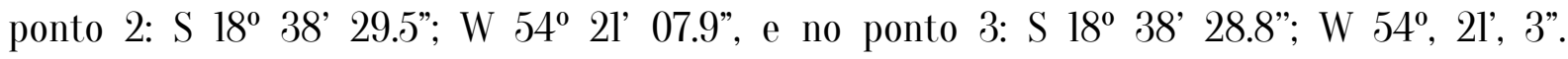
Apresentados na figura 1.

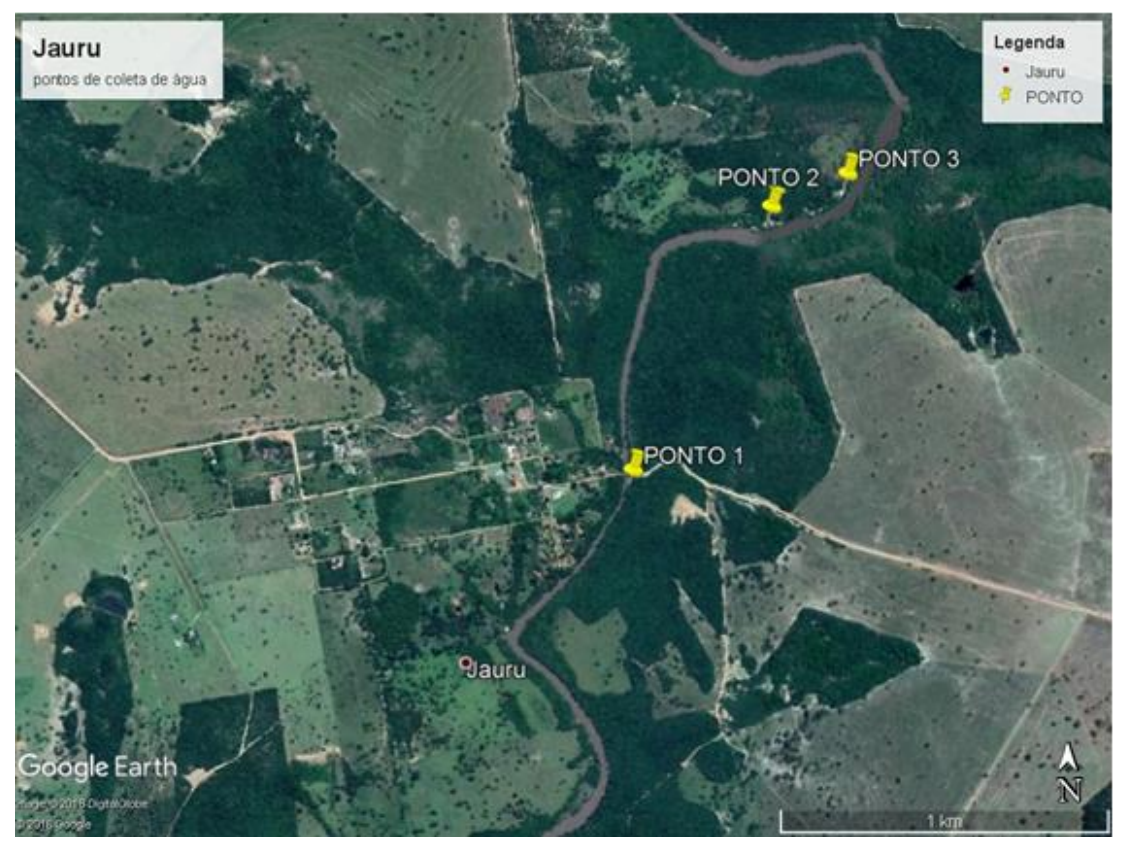

Figura 1: Vilarejo banhado pelo Rio Jauru.

Fonte: Google Earth.

0 transporte das amostras ocorreu em temperatura ambiente de $35^{\circ} \mathrm{C}$, para os dois primeiros meses a estação predominante era a seca e o último mês corresponde ao período chuvoso. 0 material utilizado na coleta era de plástico, sendo coletados 2 litros de amostra em cada ponto de coleta em cada mês de análise. Em relação a limpeza de todo o material foi utilizado detergente neutro, lavados também por seis vezes com água destilada, emergindo em uma solução de ácido nítrico 10\% (v/v) - Sigma-Aldrich Brasil e mantidos por 12 horas. Nessas condições, após a retirada do banho, o material recebeu água destilada e enxaguado com água deionizada, sendo que toda a água utilizada nesse estudo passou pelo Ultra purificador Water 
System, Marte (resistividade de 18,2 M. W.cm-1). Todas ás amostras obtidas foram mantidas sob refrigeração à temperatura de $20^{\circ} \mathrm{C}$ até ás análises.

A preparação das amostras para a determinação dos parâmetros físico-químicos e avaliação dos metais potencialmente tóxicos seguiu o fluxograma disposto na figura 2.

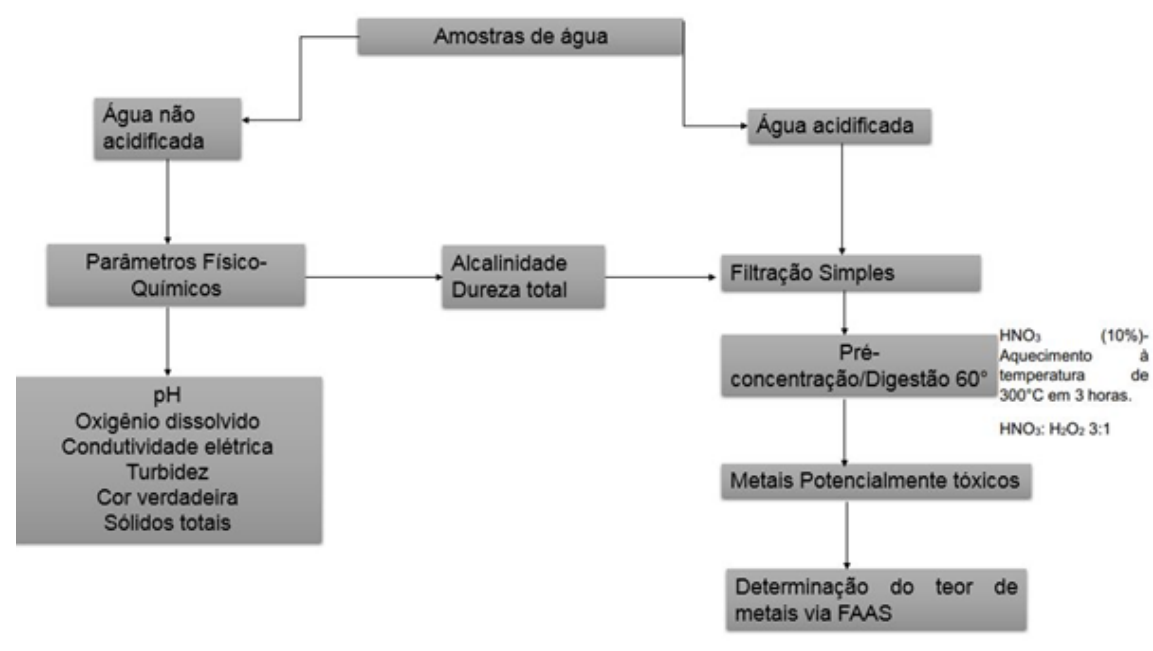

Figura 2: Etapas utilizadas na preparação das amostras de água para a determinação dos parâmetros físico-químicos e dos metais.

Fonte: Elaborado pelos autores.

As análises de alcalinidade, pH, cor verdadeira, turbidez foram adaptadas do manual prático de análise de água (BRASIL, 2013), a determinação de sólidos totais dissolvidos foi adaptada dos procedimentos internacionais da APHA et al (1992), enquanto ás demais análises físico-químicas seguiram a metodologia do fabricante do equipamento utilizado nas análises, sendo que todas análises ocorreram em triplicatas.

A determinação do pH ocorreu com a medição por meio do pHmetro mPA210 MS Tecnopon com eletrodo previamente calibrados com padrões do fabricante de 4 e 7 . A análise do oxigênio dissolvido ocorreu como o medidor de oxigênio digital portátil, M0-900 da Instrutherm. A condutividade foi obtida a partir do módulo de condutividade 856, metrohm calibrado com o padrão de 146,9 $\mathrm{\mu S} / \mathrm{cm}$ (MS- Tecnopon). Em relação a turbidez utilizou-se do turbímetro AP 2000 da Policrontrol, calibrado com os padrões de 20, 100 e 800 (NTU= Unidade Nefelométrica de Turbidez) - da Speesol.

Com o colorímetro DM-COR, digimed microprocessado, previamente calibrado com a solução de platina-cobalto da Speesol determinou-se a cor verdadeira das amostras. Para a análise dos sólidos totais dissolvidos transferiu-se $100 \mathrm{~mL}$ em uma alíquota para a cápsula de porcelana, o material foi evaporado na chapa aquecedora Lucadema, por três horas à 
Avaliação físico-química e quantificação de metais potencialmente tóxicos em águas superficiais do rio Jauru

temperatura de $300^{\circ} \mathrm{C}$. Para auxiliar na evaporação a cápsula foi alocada no dessecador por vinte e quatro horas, sendo que o teor de sólidos totais foi obtido pela diferença de massa.

A priori filtraram-se as amostras para retirada do material particulado e preparo para as análises de alcalinidade e dureza total. Em seguida a alcalinidade foi obtida com o titulador potenciométrico, titrino plus 848 metrohm com padrão de ácido clorídrico -HCl 0,1M (Synth A.C.S). A análise da dureza total ocorreu por meio do método Mll do Food Pac da Metrohm, com titulação potenciométrica a partir da solução de EDTA- ácido etilenodiamino tetra-acético (C10H16N208) - (Synth - A.C.S), e $20 \mathrm{ml}$ da solução de Tris (hidroximetil) aminometrado (C4H11N03) - (Synth - A.C.S), padronizado com carbonato de cálcio.

A avaliação dos metais potencialmente tóxicos ocorreu a partir da construção de curvas analíticas com às soluções padrões da PerkinElmer. A avaliação de $\mathrm{Ni}, \mathrm{Cd}, \mathrm{Cu}, \mathrm{Mn}$ e $\mathrm{Pb}$ ocorrem por espectrometria de absorção atômica em chama (FAAS) PerkinelmerPinAAcle 900T. As condições instrumentais foram: chama de ar/acetileno, lâmpada de deutério para a correção do fundo, taxa de aspiração de 2,0 ml.min-1, bem como, lâmpada de cátodo oco multielementar com os comprimentos de onda (níquel), $232 \mathrm{~nm}$, (cobre), 324,75 nm, (cádmio), 228,80 nm (manganês), 279.48 nm, (chumbo), 283,31 nm. E as concentrações utilizadas foram respectivamente $10 \mu \mathrm{L}, 30 \mu \mathrm{L}, 50 \mu \mathrm{L}, 100 \mu \mathrm{L}, 200 \mu \mathrm{L}$ e $300 \mu \mathrm{L}$, para cada metal analisado, todas as análises de metais foram antecedidas de um branco analítico.

0 tratamento de dados ocorreu a partir da estatística descritiva auxiliado pelo programa Origin (9.5.5).

\section{RESULTADOS E DISCUSSÃ0}

A confiabilidade do método se baseou na construção de curvas analíticas, que de acordo com Brasil (2003) elas devem apresentar valor mínimo de coeficiente de determinação de 0,99. Foram obtidos os seguintes valores R2=0,9982 (Níquel), R2=0,9987 (Cobre), R2=0,9947 (Cádmio), R2=0,9972(Manganês), R2=0,9991 (Chumbo). Os resultados obtidos para os parâmetros físico-químicos estão apresentados na tabela 1 .

Durante o período de análise, o pH não apresentou uma diferença significativa em sua amplitude sendo que a variação se encontrou entre 6,9 e 7,1 no qual essa quantificação indica proximidade com a neutralidade com uma tendência ligeiramente básica. Valores semelhantes foram obtidos por Euba-Neto et al (2012) na análise de águas utilizadas para a recreação em um balneário localizado em Caxias, Maranhão, no qual os pontos de análise estavam próximo 
da neutralidade. No presente estudo o pH encontra-se dentro dos limites máximos permitidos pela legislação.

Em relação à alcalinidade, não existe legislação que indique sua concentração máxima permitida em águas superficiais. Ela apresentou amplitudes entre 7,9 a 15,6 mg/L. Sendo que a sua quantificação apresentou valores baixos quando comparados com outras pesquisas tais como a de Andrade (2011); e Freitas et al (2008), no qual ambas análises apontaram para 0 aumento da concentração de alcalinidade devido ação antrópica no meio. No entanto, cabe ressaltar que para alcalinidade não há legislação que indique a concentração máxima permitida em águas superficiais.

Tabela 1. Parâmetros Físico-Químicos do Rio Jauru.

\begin{tabular}{|c|c|c|c|c|c|c|c|c|c|}
\hline P.A & Estatística & $\mathrm{pH}$ & $\begin{array}{l}\text { A.L } \\
(\mathrm{mg} / \mathrm{L})\end{array}$ & $\begin{array}{l}\text { O.D } \\
(\mathrm{mg} / \mathrm{L})\end{array}$ & $\begin{array}{l}\text { C.E } \\
(\mu \mathrm{s} / \mathrm{cm})\end{array}$ & $\begin{array}{l}\text { T. U } \\
\text { (NTU) }\end{array}$ & $\begin{array}{l}\text { S.T. D } \\
(\mathrm{mg} / \mathrm{L})\end{array}$ & $\begin{array}{l}\mathrm{C} . \mathrm{Ve} \\
(\mathrm{mg} / \mathrm{L})\end{array}$ & $\begin{array}{l}\text { D.T } \\
(\mathrm{mg} / \mathrm{L})\end{array}$ \\
\hline \multirow[t]{5}{*}{1} & Max & 7,1 & 15,6 & 8,2 & 25,5 & 32,2 & 100,0 & 99,0 & 6,7 \\
\hline & Min & 6,9 & 9,8 & 6,8 & 11,5 & 12,2 & 44,0 & 47,8 & 5,2 \\
\hline & MD & 7,0 & 11,9 & 7,3 & 18,0 & 21,7 & 68,0 & 69,0 & 6,0 \\
\hline & $\mathrm{Sd}$ & 0,1 & 3,2 & 0,7 & 7,0 & 10,0 & 28,9 & 26,7 & 0,8 \\
\hline & C.V & 1,7 & 27,4 & 10,0 & 38,9 & 0,4 & 42,4 & 38,8 & 13,0 \\
\hline \multirow[t]{5}{*}{2} & Max & 7,2 & 15,3 & 8,2 & 25,0 & 48,4 & 95,5 & 95,8 & 6,8 \\
\hline & Min & 6,9 & 7,9 & 6,8 & 20,1 & 12,2 & 38,0 & 64,6 & 5,5 \\
\hline & MD & 7,0 & 11,4 & 7,2 & 22,4 & 26,7 & 64,5 & 75,1 & 6,3 \\
\hline & $\mathrm{Sd}$ & 0,13 & 3,7 & 0,2 & 2,4 & 19,1 & 29,0 & 17,9 & 0,6 \\
\hline & C.V & 1,9 & 32,2 & 2,3 & 9,3 & 71,6 & 45,0 & 23,8 & 10,6 \\
\hline \multirow[t]{5}{*}{3} & Max & 7,3 & 15,2 & 7,9 & 24,5 & 45,3 & 76,5 & 94,0 & 6,6 \\
\hline & Min & 6,9 & 10,6 & 6,8 & 11,9 & 12,2 & 44,0 & 47,8 & 4,8 \\
\hline & MD & 7,0 & 12,3 & 7,1 & 18,5 & 25,2 & 54,8 & 66,1 & 5,5 \\
\hline & $\mathrm{Sd}$ & 0,2 & 2,5 & 0,6 & 6,3 & 17,5 & 16,2 & 24,5 & 0,9 \\
\hline & C.V & 3,7 & 20,2 & 8,8 & 34,0 & 69,4 & 29,6 & 37,1 & 16,9 \\
\hline R.E & C.0 $357(2005)$ & $\begin{array}{ll}6,0 & \text { a } \\
9,0 & \end{array}$ & $\mathrm{Au}$ & $>4$ & $\overline{\mathrm{Au}}$ & 100 & 500 & 75 & $\overline{\mathrm{Au}}$ \\
\hline
\end{tabular}

P.A= Ponto de Amostragem. Max= Máximo. Min=Mínimo. MD=Média. Sd= Desvio Padrão da Média. C.V= Coeficiente de Variação. R.E= Resolução. $C .0=$ Conama. $\mathrm{pH}=$ Potencial Hidrogeniônico. A.L= Alcalinidade. $0 . \mathrm{D}=$ Oxigênio Dissolvido. C.E = Condutividade Elétrica. T.U= Turbidez. S.T = Sólidos Totais Dissolvidos. C.Ve= Cor Verdadeira. D.T=Dureza Total. Au=Ausente.

Fonte: Elaborado pelos autores.

0 oxigênio dissolvido apresentou valores de 6,8 a $8,2 \mathrm{mg} / \mathrm{L}$ estando acima da concentração mínima requerida pela resolução do Conama (BRASIL, 2005). Nesse sentido, o oxigênio dissolvido é um dos fatores de indicação da qualidade ambiental do bioma, pois valores abaixo do limite estipulado levariam à mortandade dos peixes afetando não apenas o comércio do vilarejo, mas toda a cadeia alimentar do rio. Valores abaixo do estipulado pela resolução do Conama (BRASIL, 2005), apontariam para a interferência humana no intrincado 
Avaliação físico-química e quantificação de metais potencialmente tóxicos em águas superficiais do rio Jauru

ciclo de introdução do oxigênio dissolvido, ocasionados com o lançamento de esgoto e poluentes provenientes da indústria, porém essa região não apresenta atividade industrial.

A condutividade elétrica apresentou uma variação entre 11,5 a 25,5 $\mathrm{\mu s} / \mathrm{cm}$, sendo que os valores máximos para a condutividade elétrica estão ausentes na resolução do Conama. Entretanto ao comparar os valores encontrados com o estipulado pela Companhia Ambiental do Estado de São Paulo (CETESB-2010), que considera que corpos hídricos com impactos antropogênicos apresentam valores acima de 100 s/cm. Já Renovato, Sena e Silva (2013), apontaram que a condutividade indica modificações na composição da água representando ambientes com alta probabilidade de impactos de poluentes. Apesar disso a quantificação expressa na Tabela 1 não indica 0 impacto direto de poluentes pelo presente parâmetro.

Por meio da estatística descritiva obteve-se que em termos de média, desvio padrão e coeficiente de variação apresentados na Tabela $10 \mathrm{pH}$ apresenta baixa variação nos valores entre os pontos de análise, indicando um sistema aquático que não sofre variações bruscas de $\mathrm{pH}$.

A alcalinidade e a condutividade elétrica foram os parâmetros que mais apresentaram variação para o coeficiente de correlação, sendo possível indicar que esses parâmetros estejam influenciados pelos processos naturais, tais como, o carreamento de partículas do solo para 0 leito do rio que ocasionaram o aumento da concentração.

Em relação à turbidez os valores apresentados foram de 12,2 a 48,4 NTU, sendo que esses valores estão próximos aos obtidos no estudo de Falqueto (2008) em águas superficiais. Esse parâmetro decorre em função de partículas em estado de suspensão, sendo principalmente plâncton, argila, areia e poluição diversa. As condições geológicas da bacia do Rio Jauru propiciam a presença de materiais particulados em águas superficiais, causando variação organoléptica visual (BRASIL, 2006). Apesar dessas características a turbidez encontra-se dentro do valor máximo estipula pelo Conama (BRASIL, 2005).

Os sólidos totais dissolvidos apresentam uma variação entre 38 a $100 \mathrm{mg} / \mathrm{L}$, essa variabilidade pode estar relacionada a lixiviação dos solos para a cabeceira do rio apresentando um indicativo do desmatamento ciliar uma vez que à ausência da cobertura vegetal aumenta o carreamento de partículas para o leito do rio. Porém é importante ressaltar que mesmo as concentrações obtidas para os sólidos totais dissolvidos estarem abaixo do permitido pela legislação existem diversos pontos de erosão ocasionados pelo fato do gado consumir a água do rio contribuindo assim para o lançamento de partículas nas águas. Os sólidos totais dissolvidos possuem ainda capacidade de reter bactérias e diversos resíduos que 
estimulam a decomposição da matéria orgânica, acarretando a diminuição do oxigênio dissolvido (CETESB, 2016). A baixa concentração de sólidos totais apresenta consonância com os níveis do oxigênio dissolvido que estão dentro dos parâmetros de qualidade.

A cor verdadeira está relacionada com o aspecto visual da água que pode provocar uma repulsão por parte de consumidores. Esse parâmetro apresentou valores de 47,8 a $99 \mathrm{mg} / \mathrm{L}$, com a concentração máxima desse parâmetro acima do valor máximo permitido. Um dos fatores que está relacionado a esse aumento trata-se das substâncias húmicas que advém do processo de degradação da matéria vegetal, levando às reações químicas e biológicas devido à presença de componentes orgânicos naturais nas águas, dentre essas os ácidos húmicos e ácidos fúlvicos (MIRANDA, et al, 2009).

Os demais fatores que poderiam justificar as concentrações acima do permitido tais como o carreamento de material sólido em suspensão deveria ocasionar no aumento dos demais parâmetros em especial a turbidez, fato esse não observado na Tabela 1, além disso a pluviosidade não contribuiu com o aumento da concentração pois os parâmetros sensíveis como a condutividade, turbidez e os sólidos totais dissolvidos não apresentaram concentrações acima do permitido.

A dureza total apresentou variações de 4,8 a $6,8 \mathrm{mg} / \mathrm{L}$, não sendo apresentado 0 valor máximo permitido para esse parâmetro na resolução do Conama (BRASIL, 2005). A portaria do ministério da saúde $n^{0} 2.914$ de 12 de dezembro de 2011 (BRASIL, 2011), estipulou para águas utilizados no consumo humano o valor máximo de $500 \mathrm{mg} / \mathrm{L}$. Veiga (2005) apontou que a dureza total apresenta níveis que são classificados em Águas moles <50 mg CaC03/L (Carbonato de Cálcio), Águas de dureza moderada entre 50 e $150 \mathrm{mg}$ CaC03/L, Águas duras entre 150 e $300 \mathrm{mg} \mathrm{CaC03/L,} \mathrm{Águas} \mathrm{muito} \mathrm{duras} \mathrm{>300} \mathrm{CaC03/L.} \mathrm{Comparando} \mathrm{esses} \mathrm{valores} \mathrm{com}$ a da Tabela 1 verifica-se que a quantificação indica água mole com traços de cálcios e magnésio nas águas. Porém as baixas concentrações apontam para ausência de alcalinos terrosos ligados a sulfetos que corresponderiam no aumento da dureza total.

A estatística descritiva apontou que a turbidez apresentou valores mínimo e máximos com intervalos elevados, essa variabilidade está relacionado ao fato do rio servir para a dessedentação de animais em especial o gado de corte. Essa variação da amplitude também é observada nos demais parâmetros com exceção da cor verdadeira que apresentou concentrações elevadas devido aos fatores naturais, enquanto para a dureza total os cátions Ca2+ e Mg2+ não compõem a estrutura geológica da região, apresentando pouca variação na Tabela 1. 
Avaliação físico-química e quantificação de metais potencialmente tóxicos em águas superficiais do rio Jauru

Em relação à atividade mineradora em garimpos, apesar de existirem vem apresentando uma diminuição e concentra-se na exploração de diamantes, com a presença de um veio de exploração próximo ao ponto 3 de análise. Apesar disso os parâmetros analisados não apresentaram valores bruscos de concentração, entretanto é importante frisar que a exploração de minerais não deve ser descartada completamente como fator de impacto ambiental.

A Tabela 2 apresenta os valores máximos, mínimos, médios 0 desvio padrão e 0 coeficiente de variação para os metais nas águas superficiais do Rio Jauru.

Tabela 2. Avaliação de Metais no Rio Jauru.

\begin{tabular}{|c|c|c|c|c|c|c|}
\hline P.A & Estátistica & $\begin{array}{c}\mathrm{Cu} \\
(\mu \mathrm{g} . \mathrm{L})\end{array}$ & $\begin{array}{c}\mathrm{Ni} \\
(\mu \mathrm{g} . \mathrm{L})\end{array}$ & $\begin{array}{c}\text { Cd } \\
(\mu \mathrm{g} . \mathrm{L})\end{array}$ & $\begin{array}{c}M n \\
(\mu g . L)\end{array}$ & $\begin{array}{c}\mathrm{Pb} \\
(\mu \mathrm{g} . \mathrm{L})\end{array}$ \\
\hline \multirow[t]{5}{*}{1} & Max & 0,014 & ND & ND & 0,014 & ND \\
\hline & Min & 0,009 & ND & ND & 0,010 & ND \\
\hline & MD & 0,011 & ND & ND & 0,011 & ND \\
\hline & $\mathrm{Sd}$ & 0,002 & ND & ND & 0,002 & ND \\
\hline & C.V & 18,181 & ND & ND & 18,181 & ND \\
\hline \multirow[t]{5}{*}{2} & Max & 0,020 & ND & ND & 0,008 & ND \\
\hline & Min & 0,009 & ND & ND & 0,010 & ND \\
\hline & MD & 0,013 & ND & ND & 0,010 & ND \\
\hline & $\mathrm{Sd}$ & 0,005 & ND & ND & 0,003 & ND \\
\hline & C.V & 38,461 & ND & ND & 30,000 & ND \\
\hline \multirow[t]{5}{*}{3} & Max & 0,010 & ND & ND & 0,013 & ND \\
\hline & Min & 0,007 & ND & ND & 0,009 & ND \\
\hline & MD & 0,008 & ND & ND & 0,011 & ND \\
\hline & $\mathrm{Sd}$ & 0,001 & ND & ND & 0,002 & ND \\
\hline & C.V & 12,500 & ND & ND & 18,181 & ND \\
\hline R.E & $\begin{array}{l}\text { C.O } 357 \\
(2005)\end{array}$ & 0,013 & 0,025 & 0,010 & 0,50 & 0,033 \\
\hline
\end{tabular}

P.A= Ponto de Amostragem. Max= Máximo. Min= Mínimo. MD=Média. Sd= Desvio Padrão da Média. C.V= Coeficiente de Variação. R.E= Resolução. C.0= Conama. ND= Valores Não Determinados.

Fonte: Elaborado pelos autores.

Na quantificação do cobre este apresentou valores acima dos limites estabelecidos pela resolução do Conama (BRASIL, 2005), para águas doces de classe 3 em dois pontos. Somandose a isso é importante considerar que a ingestão desse metal em excesso ocasiona de acordo com Venezuela (2001): salivação, náusea, insuficiência renal, diarreia, além da doença de Wilson que provoca a dilatação do fígado, fortes dores durante a locomoção.

Um dos possíveis indicativos da presença de cobre nos pontos detectados pode estar relacionado ao teor natural de cobre no solo, que vai ao encontro com a concepção de Mantovani (2009), no qual a formação do solo da região é um indicativo das características 
físico-química presentes nas rochas. Esses fatores propiciam a presença de cobre associado à alguns mineraloídes, tais como a calcopirita (CuFeS2), bornita (Cu5FeS4), e tetraedrita $(\mathrm{Cu}, \mathrm{Fe}) 12 \mathrm{Sb} 4 \mathrm{Sl3}$, presentes em quantidades de traços na região, com isso o processo de desgaste, por intemperismo natural é uma das possibilidades que permitiram detectar o teor de cobre. 0 carreamento de material particulado com agrotóxicos levaria ao aumento da concentração não apenas do cobre, mas também dos demais metais analisados.

Porém, os metais ( $\mathrm{Ni}, \mathrm{Cd}$ e $\mathrm{Pb}$ ) encontram-se abaixo do limite de quantificação do espectrofotômetro, e no momento do estudo nas áreas de análise, esses pontos não estavam recebendo impactos dos metais empregados nos agrotóxicos nas monoculturas. Além disso, a região Norte de Mato Grosso do Sul, não apresenta atividade industrial intensa que poderia elucidar a quantificação de metais no rio. No que tange a exploração de minerais na região concentra-se atualmente no diamante, não sendo empregado metais potencialmente tóxicos, em sua separação sendo que persistem poucos garimpos no leito do rio. A variação da estação seca para a chuvosa não foi suficiente para quantificar esses metais.

Os valores obtidos para o manganês estão em todos os pontos da coleta, abaixo do valor máximo permitido pelo Conama. A presença desse metal pode estar relacionada ao seu processo de absorção em minerais da argila, pois segundo Sampaio (2003) os latossolos predominantes na região apresentam teores de óxidos e hidróxidos de manganês que são indicativo da presença desse metal na quantificação apresentado na Tabela 2.

As concentrações de cobre nos pontos analisados não demonstram variações significativas considerando o período de amostragem. Em relação a quantificação do manganês não foi observado uma amplitude significativa desse metal.

\section{CONCLUSÃO}

Os resultados apresentados na Tabela 1 indicam que a maior parte dos parâmetros analisados não apresentam desvios quando comparados com as legislações do Conama (BRASIL, 2005); CETESB (2010); e da portaria do ministério da saúde $\mathrm{n}^{0} 2.914$ de 12 de dezembro de 2011 (BRASIL, 2011). Apenas a cor verdadeira encontra-se acima do valor máximo permitido devido ao processo natural das substâncias húmicas no meio aquático. Por ser um parâmetro organoléptico os consumidores podem apresentar repulsa pelo consumo dessa água, levando a busca por outras fontes como as reservas subterrâneas para suprir a demanda por água. 
Avaliação físico-química e quantificação de metais potencialmente tóxicos em águas superficiais do rio Jauru

A mudança de estação da seca para a chuvosa não constituiu como um indicativo do aumento da concentração dos parâmetros, bem como, a atividade mineradora não impactou no momento do estudo os pontos analisados.

Na determinação dos metais nas amostras, apenas o cobre apresentou valores acima do permitido pelo Conama (BRASIL, 2005), possivelmente devido a estrutura geológica dos solos. Os outros metais quantificados (níquel, cádmio, manganês e chumbo), apresentaram concentrações abaixo do limite estabelecido pela resolução do Conama, bem como, dos limites de quantificação do instrumento.

Em relação a estação chuvosa está não influenciou na quantificação dos metais pois não ocorreu uma variação significativa nessa estação.

Diante dos resultados expostos no presente estudo, não há um indicativo de contaminação ambiental nos pontos e nos meses de análise, entretanto reiteramos a necessidade de monitoramento do Rio Jauru, quanto aos parâmetros físico-químicos e de metais nas águas superficiais devido as extensas monoculturas na região, bem como, a pecuária de corte e dos pequenos garimpos que se localizam nas proximidades do rio.

\section{REFERÊNCIAS BIBLIOGRÁFICAS}

AMARAL, M, A, B. Poluição dos solos por metais pesados na zona urbana de ponta delgada: Implicações na saúde pública. 2012. 113f. Dissertação de mestrado em ciências biomédicas. Universidade dos açores, Ponta Delgada, 2012.

ANDRADE, L. Qualidade da água potável para consumo humano na cidade de Mindelo, São Vicente-Cabo Verde, 2011. Série relatórios técnicos. Departamento de Engenharia e ciências do mar. Curso de Licenciatura em Biologia Marinha e Pescas. 2011.

APHA. (American Public Health Associantion). Standard methods for the examination of water and wastewater. 18 th edition. Washington DC.1992.

BRASIL. Ministério do Meio Ambiente, dos Recursos Hídricos e da Amazônia Legal. Plano de Conservação da Bacia do Alto Paraguai (Pantanal) - PCBAP: análise integrada e prognóstico da Bacia do Alto Paraguai. Brasília, 1997. Programa Nacional do Meio Ambiente. Projeto Pantanal.

. Agência Nacional de Vigilância Sanitária - Anvisa. Portaria No 899, de 29 de maio de 2003. Guia Para Validação de Métodos Analíticos e Bioanalíticos. Diário Oficial da República Federativa do Brasil. Brasília: 2003.

. Conselho Nacional de Meio Ambiente. Resolução CONAMA. Resolução n. 357 , de 17 de março de 2005. Dispõe sobre a classificação dos corpos de água e diretrizes ambientais para o seu enquadramento, estabelece as condições e padrões de lançamento de efluentes, e dá outras providências. Diário Oficial da República Federativa do Brasil. Brasília: MMA, 2005.

(Empresa Brasileira e Pesquisa Agropecuária- EMPRAPA). Impactos ambientais e socioeconômicos na bacia do Rio Taquari- Pantanal. 1 ed. Corumbá, 2006. 
Portaria $\mathrm{n}^{0}$ 2.914, de 12 de dezembro de 2011. Dispõe Sobre 0s Procedimentos de Controle e de Vigilância da Qualidade da água Para Consumo Humano e Seu Padrão de Potabilidade. Brasília, Disponível em: <http://bvsms.saude.gov.br/bvs/saudelegis/gm/2011/prt2914_12_12_2011.html〉. Acesso em: 08 jun. 2017.

. Fundação Nacional de Saúde. Manual prático de análise de água. 4 ed. Brasília: Funasa, 2013.

CETESB. Companhia de Tecnologia de Saneamento Ambiental do Estado de São Paulo. Significado Ambiental e Sanitário das Variáveis de Qualidade das Águas e dos Sedimentos e Metodologias Analíticas e de Amostragem. Série Relatórios. 1 ed. 2010.

Qualidade das águas superficiais no estado de São Paulo. Significado ambiental e sanitário das variáveis de qualidade das águas. Série Relatórios. 1 ed. 2016.

EUBA-NET0, M. SILVA, W.0.; RAMEIR0, F.C.; do NASCIMENTO, E.S.; ALVES, A. de. S.; Análises física, química e microbiológicas das águas do balneário Veneza na bacia hidrográfica do médio Itapecuru, MA. Arquivo do instituto de biológico. v. 79, n.3, p. 397-403, 2012.

FALQUETO, M.A. Avaliação do índice de qualidade da água (IQA) e dos elementos químicos nas águas e nos sedimentos do Rio Corumbataí- SP. 2008. 117f. Dissertação de mestrado em ecologia aplicada - Escola Superior de Agricultura (Luiz de Queiros”- Universidade de São Paulo, Piracicaba, 2008.

FERREIRA-NET0, J, F. Raízes de Coxim. 1 ed. Editora UFMS, Campo Grande. 2004.

FREITAS, T. 0.; OLIVEIRA, M, D. S.; CAIXETA, E, F. V.; ARAÚJ0, M, A, G.; VIDIGAL, L, M.; FALONE, S, Z.; Determinação da temperatura, pH e da alcalinidade total como etapas preliminar para o ensaio de coagulação para o tratamento da água do CEFET-Urutaí. In: Jornada da produção científica da educação profissional e tecnológica da região centro oeste. Anais. 2, 2008, Cuiabá. 5p.

MANTOVANI, A. Composição química de solos contaminados por cobre: Formas, Sorção e Efeito no Desenvolvimento de Espécies Vegetais. 2009. 178f. Tese de Doutorado em Agronomia. Universidade Federal do Rio Grande do Sul, Porto Alegre, 2009.

MARASCHIM, L. Avaliação do grau de contaminação por pesticidas na água dos principais rios formadores do pantanal mato-grossense. 2003. 90f. Dissertação de mestrado, em saúde e ambiente, área química ambiental. Universidade Federal de Mato Grosso, Cuiabá, 2003.

MESQUITA, G, M. Metodologias de preparo de amostras e quantificação de metais pesados em sedimentos do Ribeirão Sammbaia, Catalão-Go, empregando Espectrometria de Absorção Atômica. 2014. 134f. Dissertação de mestrado em Química. Instituto de Química, Universidade Federal de Goiás, Catalão, 2014.

MIRANDA, R. G.; PEREIRA, S, de F, P.; ALVES, D, T, V.; OLIVIEIRA, G, R, F.; Qualidade dos recursos hídricos da Amazônia - Rio Tapajós: avaliação de caso em relação aos elementos químicos e parâmetros físico-químicos. Revista Água \& Ambiente, v. 4, n. 2, p. 75092. 2009.

RENOVAT0, D, C, C.; SENA, C, P.; SILVA, M, M, F.; Análise de parâmetros físico-químicos das águas da barragem pública da cidade de pau dos ferros (RN) - pH, Cor, Turbidez, Acidez, Alcalinidade, Condutividade, Cloreto e Salinidade. In: Congresso de iniciação científica do IFRN, Anais. IX. CONGIG. 2013, Natal, IFRN, 2013, 10 p.

SAMPAI0, A, C, S. Metais pesados na água e sedimentos dos rios da bacia do Alto Paraguai. 2003. 76 f, dissertação de mestrado, Departamento de Tecnologias Ambientais, Universidade Federal de Mato Grosso do Sul, Campo Grande, 2003.

UECHI, D, A. GABAS, S, G. LASTORIA, G. Análise de metais pesados no sistema Aquífero Bauru em Mato Grosso do Sul. Engenharia sanitária ambiental. v.22, n.1, p. 155-167, 2017.

VENEZUELA, T, C. Determinação de contaminantes metálicos (metal tóxico) num solo adubado com composto de lixo em área olerícola no município de nova Friburgo. 2001. 96 f, Dissertação de mestrado, centro de saúde do trabalhado e ecologia humana, Fundação Oswald Cruz, Rio de Janeiro, 2001. 